\title{
Microdoping compensation of microcrystalline silicon obtained by Hot-Wire Chemical Vapour Deposition
}

\author{
C. Voz, D. Peiró, M. Fonrodona, D. Soler, J. Bertomeu and J. Andreu \\ Universitat de Barcelona, Departament de Física Aplicada i Òptica \\ Av. Diagonal 647, Planta 4. E-08028 Barcelona (Catalonia, Spain) \\ Phone: 34-93-4021134, Fax: 34-93-4021138, e-mail: cvoz@ fao.ub.es
}

Keywords: microcrystalline silicon, Hot-Wire CVD, microdoping, solar cell.

\begin{abstract}
Undoped hydrogenated microcrystalline silicon was obtained by Hot-Wire Chemical Vapour Deposition at different silane-to-hydrogen ratios and low temperature $\left(<300^{\circ} \mathrm{C}\right)$. As well as technological aspects of the deposition process, we report structural, optical and electrical characterisations of the samples that were used as the active layer for preliminary p-i-n solar cells. Raman spectroscopy indicates that changing the hydrogen dilution can vary the crystalline fraction. From electrical measurements an unwanted n-type character is deduced for this undoped material. This effect could be due to a contaminant, probably oxygen, which is also observed in capacitancevoltage measurements on Schottky structures. The negative effect of contaminants on the device was dramatic and a compensated p-i-n structure was also deposited to enhance the cell performance.
\end{abstract}

\section{Introduction}

The high production cost of thick, high efficiency crystalline silicon (c-Si) solar cells inhibits extensive application of solar energy. In the long term thin film silicon technology should replace bulk c-Si devices for most applications which demand cheap and large area solar panels[1]. Unfortunately, the most developed thin film silicon cells, based on hydrogenated amorphous silicon (a-Si:H), suffer from inherent instability and moderate efficiencies. Attempts have been made to develop thin film c-Si solar cell technologies which fulfil the low cost, large area and stability 
requirements[2]. The approach of polycrystalline silicon with a large grain size either requires expensive substrates compatible with high temperature processes[3] or is very time consuming in recrystallisation techniques[4]. More recently, microcrystalline silicon ( $\mu \mathrm{c}-\mathrm{Si}$ ) has been successfully incorporated as the active layer in p-i-n devices by different deposition techniques. Kaneka Corporation achieved a $10.7 \%$ stable efficiency device by Plasma Enhanced Chemical Vapour Deposition (PECVD) at process temperatures lower than $600^{\circ} \mathrm{C}[5]$. In a more simple process stable efficiencies up to $8.5 \%$ have been reported by the group at the University of Neuchâtel in cells obtained by Very High Frequency PECVD (VHF-PECVD) at $200^{\circ} \mathrm{C}[6]$. Quite promising results have recently been obtained with the Hot-Wire Chemical Vapour Deposition (HWCVD) technique by the Debye Institute at the University of Utrecht[7] and efficiencies near 4\% have been reported for cells only $1.5 \mu \mathrm{m}$ thick. Since HWCVD is by far the most novel and least studied technique, it could have a greater improvement potential than the other techniques. In addition this technique has been proved to produce deposition rates in the range of some tens of $\AA / s[8]$. Our group is now studying the HWCVD technique and its viability for photovoltaic applications. Preliminary results were obtained in a provisional high vacuum (HV) set-up[8] which has recently been replaced by a ultra-high vacuum (UHV) multichamber set-up, more suitable for electronic applications. Here we discuss technological aspects of the deposition process and study undoped material and the first p-i-n devices obtained with the UHV HWCVD set up.

\section{Experimental}

Undoped $\mu \mathrm{c}-\mathrm{Si}: \mathrm{H}$ films were deposited on Corning 7059, c-Si wafer(111) and ZnO:Al-coated glass in one of the chambers of a UHV multichamber set-up with load-lock. The pumping system, which allows a base pressure lower than $10^{-8}$ mbar, consists of a turbomolecular pump (Leybold TURBOVAC 361C) and a rotatory vane pump (Leybold TRIVAC D40BCS). The gas inlet, the 
substrate holder, the shutter and a basket-shaped tungsten filament of $0.5 \mathrm{~mm}$ diameter are arranged as shown in Figure 1. The distance between the top of the filament and the substrate was $4 \mathrm{~cm}$. The filament was heated by the Joule effect and catalytic cracking reactions at its surface decomposed the silane-hydrogen mixture during the deposition, resulting in atomic species, radicals and electrons acting as deposition precursors. A series of samples with different hydrogen dilution was obtained by varying the silane/hydrogen ratio in the gas mixture and maintaining a fixed process pressure of $7 \times 10^{-3}$ mbar. The filament was heated to above $1700^{\circ} \mathrm{C}$. The power dissipated at the filament contributed to increase about $40^{\circ} \mathrm{C}$ the substrate temperature. The resulting substrate temperature was estimated to be $200^{\circ} \mathrm{C}$ from previous calibrations. The deposition rates for these samples were in the order of $2 \AA / s$.

We studied the effect of the hydrogen dilution on the crystallinity by Raman Spectroscopy (514 nm laser radiation) and Photothermal Deflection Spectrometry (PDS). The activation energy of the dark conductivity as a function of temperature revealed whether the undoped material was truly intrinsic. The $\mathrm{ZnO} / \mu \mathrm{c}-\mathrm{Si}: \mathrm{H}$ contact showed a clear rectifying behaviour and the standard Capacitance-Voltage $(C-V)$ measurement on Schottky structures[9] was performed to evaluate an effective charged trap density due to defects or contaminants. Since this value directly determines the electric field screening length in the intrinsic layer, its reduction is important to enhance the drift collection of photogenerated carriers in a solar cell. Finally, two p-i-n structures were obtained in order to compare the effect of compensating the n-character of the as deposited undoped material with controlled low flows of diborane. 


\section{Results and discussion}

\subsection{Crystallinity and intrinsic character}

Figure 2 shows the Raman spectra of two samples obtained at different hydrogen dilutions. The amorphous phase appeared as a broad band around $480 \mathrm{~cm}^{-1}$ and the TO-phonon mode of the crystalline fraction showed a sharp peak centred at $520 \mathrm{~cm}^{-1}$. The crystalline fraction was estimated by the calculation procedure proposed by Tsu et al.[10]. Results indicate that changing the hydrogen dilution can vary the crystalline fraction.

The crystalline fraction for the whole series of samples (Fig. 3) shows a monotonous increase with the hydrogen dilution. At the same time, the dark conductivity activation energy decreased. Since the c-Si band gap is $1.14 \mathrm{eV}$, an activation energy above $0.5 \mathrm{eV}$ would be expected for intrinsic samples. The most crystalline samples showed activation energies around $0.4 \mathrm{eV}$. The optical absorption was measured by PDS and the indirect optical gap was estimated from the Tauc plot ( $\alpha^{1 / 2}$ versus $\left.h v\right)$ (Fig. 4). The $1.15 \mathrm{eV}$ value obtained for the $95 \%$ hydrogen diluted sample points to a high crystalline fraction as deduced from Raman spectroscopy. The $90 \%$ diluted sample, with a lower crystalline fraction, showed an apparent gap of $1.3 \mathrm{eV}$. This indicates that the apparent nearly intrinsic behaviour obtained at dilutions lower than $90 \%$ is likely related to the amorphous phase in the samples, with higher band gap, rather than to achieving the midgap condition.

From a previous study on doped samples [11] and the sign of the thermopower an n-character was deduced for all these samples. This n-character could be attributed to the incorporation of contaminants in the films. Among the possible sources of contaminants the more likely are: i) gas phase impurities coming from gas feed (mainly oxygen), ii) metallic impurities coming from the filament (mainly tungsten), and iii) other gas phase impurities degassed from the reactor walls. Whereas other groups[12] succeeded in obtaining truly intrinsic samples by using a feed gas 
purifier, only very slight differences in the activation energy were observed in our case. This indicates that the possible contamination does not come from the gas lines. Although tungsten contamination coming from the filament could not be discarded, donor levels related to tungsten in silicon have not been detected. In addition, the analysis by Secondary Ion Mass Spectrometry (SIMS) performed to our films showed that tungsten concentration was below the detection limit $\left(10^{16} \mathrm{~cm}^{-3}\right)$ in our set-up. Therefore, the main source of contaminants can be attributed to gas phase impurities coming from the reactor walls. This assumption is supported by the increased outgassing rate observed after a HWCVD process and this would explain the generally greater concentration of impurities observed in HWCVD samples when they are compared with PECVD material[13]. The main differences between HWCVD and PECVD process are: a) much more atomic hydrogen is generated at the hot filament than in a glow discharge and b) in HWCVD process the filament radiates intensely the walls of the chamber. Chemical reactions with the atomic hydrogen generated at the filament during the process or photochemical effects due to the radiation of the filament should not be discarded and they could increase the desorption of the material deposited on the walls of the chamber.

\subsection{Effective charged trap density}

Previous results pointed to some contaminant incorporation into the samples. Actually, a problem often encountered with as-grown undoped microcrystalline silicon is its generally pronounced n-type character. It was suggested that either the rather large content of oxygen impurities or native defects within the layers could be responsible for this unwanted Fermi level shift $[14,15]$. The group at the University of Neuchâtel showed that this n-type behaviour is mainly linked to oxygen impurities[12] acting as an unwanted donor level in the gap. 
In order to quantify the charged trap density due to this contaminant, the standard C-V measurement[9] was performed on Schottky structures $\mathrm{ZnO} / \mu \mathrm{c}-\mathrm{Si}: \mathrm{H} / \mathrm{Cr}$. Since previously studied $\mathrm{Cr} / \mu \mathrm{c}-\mathrm{Si}: \mathrm{H} / \mathrm{Cr}$ structures did not show rectifying characteristics, the Schottky barrier must be due to the $\mathrm{ZnO} / \mu \mathrm{c}-\mathrm{Si}: \mathrm{H}$ interface. In the $C$ - $V$ measurement, for a uniform doping concentration and assuming that the space charge region is completely depleted, the $1 / C^{2}$ vs. $V$ plot must show a linear behaviour[9]. The effective charged trap density $\left(N_{D}\right)$ and the space charge region width $(w)$ can be deduced from the linear fit of this plot. Figure 5 shows this plot for the more crystalline sample. The effective charged trap density was in the order of $10^{17} \mathrm{~cm}^{-3}$, which corresponds to a space charge region width of about $100 \mathrm{~nm}$. The spectral response of this was fitted in the long wavelength range with an effective collection length $L_{C}$ of $120 \mathrm{~nm}$ (Fig. 6), slightly higher than the space charge region width obtained by $C-V$. Similar results were obtained for other Schottky structures tested. The corresponding values of $N_{D}, w$ and $L_{C}$ are summarised in Table 1.

The fact that $L_{C} / w$ for all the Schottky structures indicates a dominant drift-assisted collection. Therefore, the wider the space charge region is the longer the collection length would be in a solar cell with this material as active layer. This would be achieved by reducing the effective charged trap density which was in the order of $10^{17} \mathrm{~cm}^{-3}$. Since the low subgap optical absorption measured by PDS for these samples seems to indicate a defect density at least one order of magnitude lower, we conclude that this charge is trapped in shallower states due to contaminants: carbon, nitrogen and mainly oxygen[12].

\subsection{Preliminary p-i-n structures}

Two preliminary p-i-n solar cells were obtained in order to check the previous results. The intrinsic layer was only $1 \mu \mathrm{m}$ thick in both cells and neither textured TCO nor back reflector was used. By comparing the optical absorptance of a $1 \mu \mathrm{m}$ film and the solar AM1.5 spectrum (Fig. 7), a 
very small part of the solar radiation is expected to be absorbed within the active layer. Therefore good efficiencies cannot be achieved with these devices. Neither the doped layers thicknesses were previously optimised. Nevertheless the aim was to show how oxygen contamination in the active layer rapidly ruins the solar cell performance.

Conceptually, p-type microdoping can counterbalance the n-type character of as deposited $\mu \mathrm{c}-\mathrm{Si}: \mathrm{H}$. This approach was first successfully implemented in a microcrystalline photovoltaic device[16] by the group at the University of Neuchâtel. We have also found that B/Si atomic ratios in gas phase in the order of $10^{-5}$ yield activation energies near midgap and lower room temperature dark conductivities [11]. Hence, one of the devices was compensated by depositing the intrinsic layer with a controlled low flow of diborane. Figure 8 compares the $I-V$ curves of both cells under an irradiance of $100 \mathrm{~mW} / \mathrm{cm}^{2}$. There is no significant difference in the open circuit voltage but the short circuit current is raised from 5.5 to more than $8 \mathrm{~mA} / \mathrm{cm}^{2}$. Collection was clearly better at longer wavelengths (Fig. 9) for the compensated structure[12]. The conclusion is that the negatively charged acceptors due to the boron incorporation counterbalance the positively charged donors associated with oxygen contamination. The result is a reduced effective charged trap density and therefore an enhancement in the electric field within the active layer. A high internal electric field is essential for a drift-assisted collection device as a p-i-n structure with a low mobility active layer.

\section{Conclusions}

By the HWCVD technique hydrogenated microcrystalline silicon can be obtained at low temperatures $\left(<300^{\circ} \mathrm{C}\right)$. Therefore cheap substrates can be used if low cost requirements must be fulfilled. Even though better efficiencies have been achieved with other deposition techniques, HWCVD is at a clearly earlier stage of development and it should have a greater improvement potential. Our group is nowadays studying this novel deposition process and its viability for 
photovoltaic applications. A monotonous increase in crystallinity with the hydrogen dilution was observed and crystalline fractions higher than $90 \%$ are easily obtained. The samples showed an unwanted n-character due to the incorporation of contaminants, mainly oxygen, during growth. An effective charged trap density of the order of $10^{17} \mathrm{~cm}^{-3}$ was deduced from $C$ - $V$ measurements on $\mathrm{ZnO} / \mu \mathrm{c}-\mathrm{Si}: \mathrm{H}$ Schottky contacts. This value determines the electric field screening length in the active layer of a solar cell and consequently the drift-assisted collection of photogenerated carriers. The microdoping approach was used in order to enhance the performance of preliminary $\mathrm{p}-\mathrm{i}-\mathrm{n}$ structures. Encouraging results were obtained at a very early stage of our research. Anyway the microdoping technique seems difficult to handle, especially for potential industrial applications. Much effort should be done in the future in order to identify the origin of the contamination. We must also study cleaner deposition conditions with higher gas flows and process pressures since higher deposition rates would reduce the oxygen incorporation into the samples. 


\section{References}

[1] M. A. Green, Prog. Photovolt. Res. Appl., 2, 87-94 (1994).

[2] Z. Shi and S. R. Wenham, Prog. Photovolt. Res. Appl., 2, 153-162 (1994).

[3] M. Pauli, M. Doscher, G. Salentiny, F. Homberg and J. Muller, $11^{\text {th }}$ EC Photovoltaic Solar Energy Conference, Montreux, 525 (1992).

[4] T. Matsuyama, T. Baba, T. Takahama, S. Tsuda, H. Nishiwaki and S. Tsuda, $13^{\text {th }}$ European Photovoltaic Solar Energy Conference and Exhibition, Nice, (1995).

[5] K. Yamamoto, M. Yoshimi, T. Suzuki, Y. Tawada, T. Okamoto \& A. Nakajima, $2^{\text {nd }}$ World Conf. on Photovoltaic Solar Energy Conversion, Vienna, Volume II, 1284-1289, (1998).

[6] J. Meier, H. Keppner, S. Dubail, Y. Ziegler, L. Feitknecht, P. Torres, Ch. Hof, U. Kroll, D. Fischer, J. Cuperus, J.A. Anna Selvan and A. Shah, $2^{\text {nd }}$ World Conf. on Photovoltaic Solar Energy Conversion, Vienna, Volume I, 375-379 (1998).

[7] J. K. Rath, A.J.M.M van Zutphein, H. Meiling, R.E.I. Schropp, Mat. Res. Soc. Symp. Proc. 467, 445 (1997).

[8] J. Cifre, J. Bertomeu, J. Puigdollers, M.C. Polo, J. Andreu, A. Lloret, Appl. Phys. A 59, 645-651 (1994). [9] E.H. Rhoderick, Metal-Semiconductor Contacts, Clarendon Press, Oxford (1978).

[10] R. Tsu, J. González-Hernández, S.S. Chao, S.C. Lee, K. Tanaka, Appl. Phys. Lett. 40, 534-535 (1982).

[11] C. Voz, D. Peiró, J. Bertomeu, D. Soler, M. Fonrodona, J. Andreu, Mat. Sci. \& Eng. B 69/70, 281-286 (1999).

[12] P. Torres, J. Meier, R. Flückiger, U. Kroll, J. A. Anna Selvan, H. Keppner and A. Shah. Appl. Phys. Lett., Vol. 69, 1373-1375 (1996).

[13] M.B. Schubert, R. Brüggemann, G. Bilger, A. Hierzenberger, $2^{\text {nd }}$ World Conf. on Photovoltaic Solar Energy Conversion, Vienna, Volume I, 835-837 (1998).

[14] C. Wang and G. Lucovsky, Proceedings of $21^{\text {st }}$ IEEE PVSEC, New York, 1614, (1990).

[15] G. Lucovsky, C. Wang, M. J. Williams, Y. L. Chen and D. M. Maher, Mater. Res. Soc. Symp. Proc. 283, 443 (1993). 
[16] J. Meier, R. Flückiger, H. Keppner and A. Shah, Appl. Phys. Lett. 65, 860 (1994). 
Table 1. Values of the effective charge density $\left(N_{D}\right)$, space charge region width $(w)$ and effective collection length $\left(L_{C}\right)$ for the studied Schottky structures.

\begin{tabular}{cccc}
\hline Sample & $N_{D}\left(\mathrm{~cm}^{-3}\right)$ & $w(\mathrm{~nm})$ & $L_{C}(\mathrm{~nm})$ \\
\hline$\# 1$ & $1.0 \times 10^{17}$ & 100 & 120 \\
$\# 2$ & $1.5 \times 10^{17}$ & 70 & 80 \\
$\# 3$ & $3.7 \times 10^{17}$ & 40 & 60 \\
\hline
\end{tabular}




\section{Figure captions}

Fig. 1. Arrangement of the different elements inside the HWCVD chamber.

Fig. 2. Raman spectra of two samples with thicknesses around $1 \mu \mathrm{m}$ obtained at filament temperature of $1700^{\circ} \mathrm{C}$, substrate temperature of $200^{\circ} \mathrm{C}$, process pressure of $7 \times 10^{-3} \mathrm{mbar}$ and different hydrogen dilutions.

Fig. 3. Crystalline fraction deduced from Raman spectroscopy and dark conductivity activation energies for a series of samples deposited for different hydrogen dilutions.

Fig. 4. Square root dependence of the absorption coefficient measured by Photothermal Deflection Spectroscopy for the samples shown in Fig. 2.

Fig. 5. Capacitance-Voltage measurement on a Schottky structure. From the linear fit of experimental data, the effective charged trap density $\left(N_{D}\right)$ and the space charge region width $(w)$ can be deduced.

Fig. 6. Quantum efficiency of the Schottky structure shown in Fig. 5. From the fit of the long wavelength range, an effective collection length can be obtained.

Fig. 7. Comparison of the optical absorptance of a $1 \mu \mathrm{m}$ thick layer with the solar AM1.5 spectrum, showing the optical limitations of the studied p-i-n structures.

Fig. 8. $I$ - $V$ curves for the compensated and not compensated p-i-n structures with $1 \mu \mathrm{m}$ thick intrinsic layers under an irradiance of $100 \mathrm{~mW} / \mathrm{cm}^{2}$.

Fig. 9. Quantum efficiencies of the same cells of Fig. 8. An enhanced collection for longer wavelengths is evidenced in the compensated solar cell. 


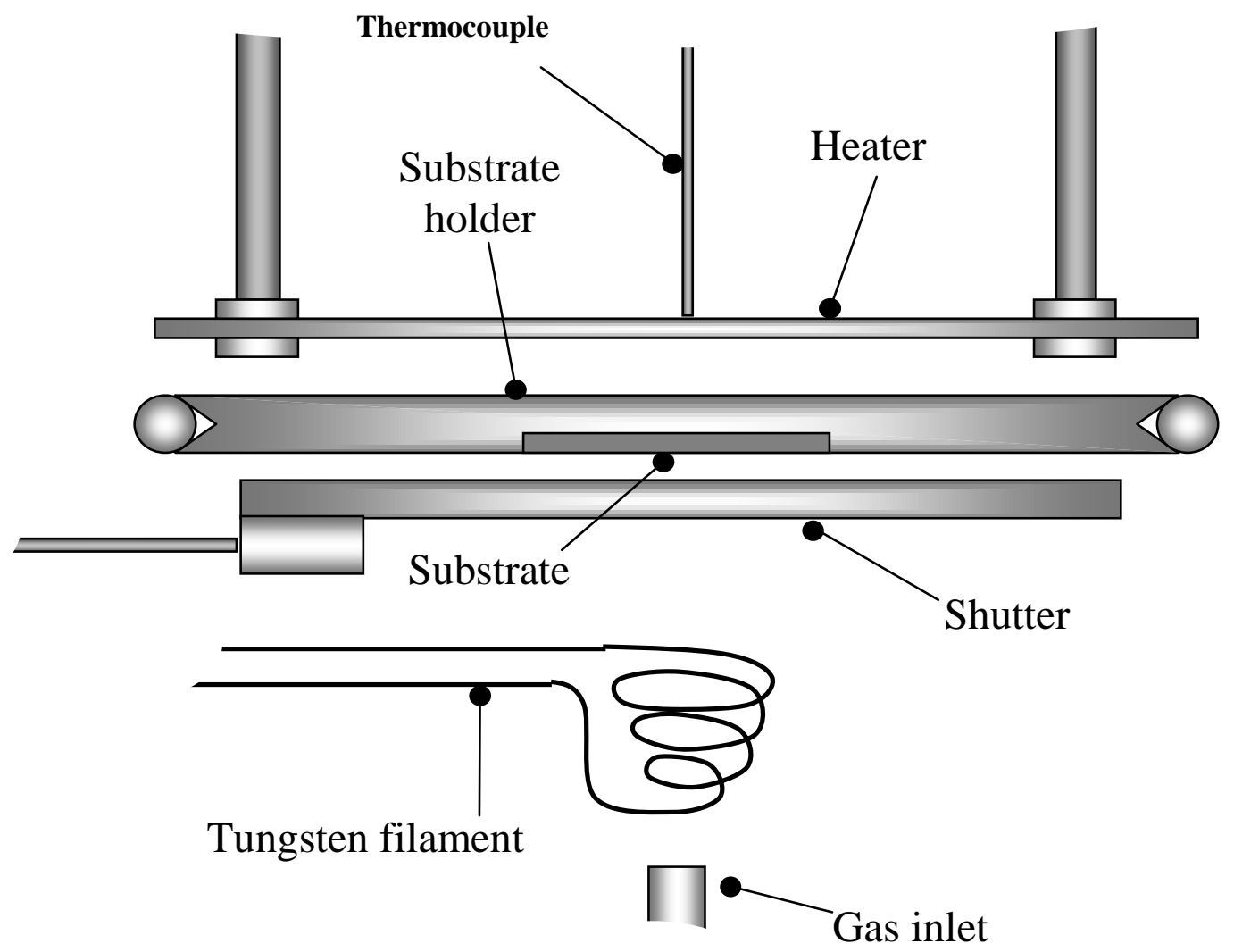

Fig. 1. C.Voz et al. 


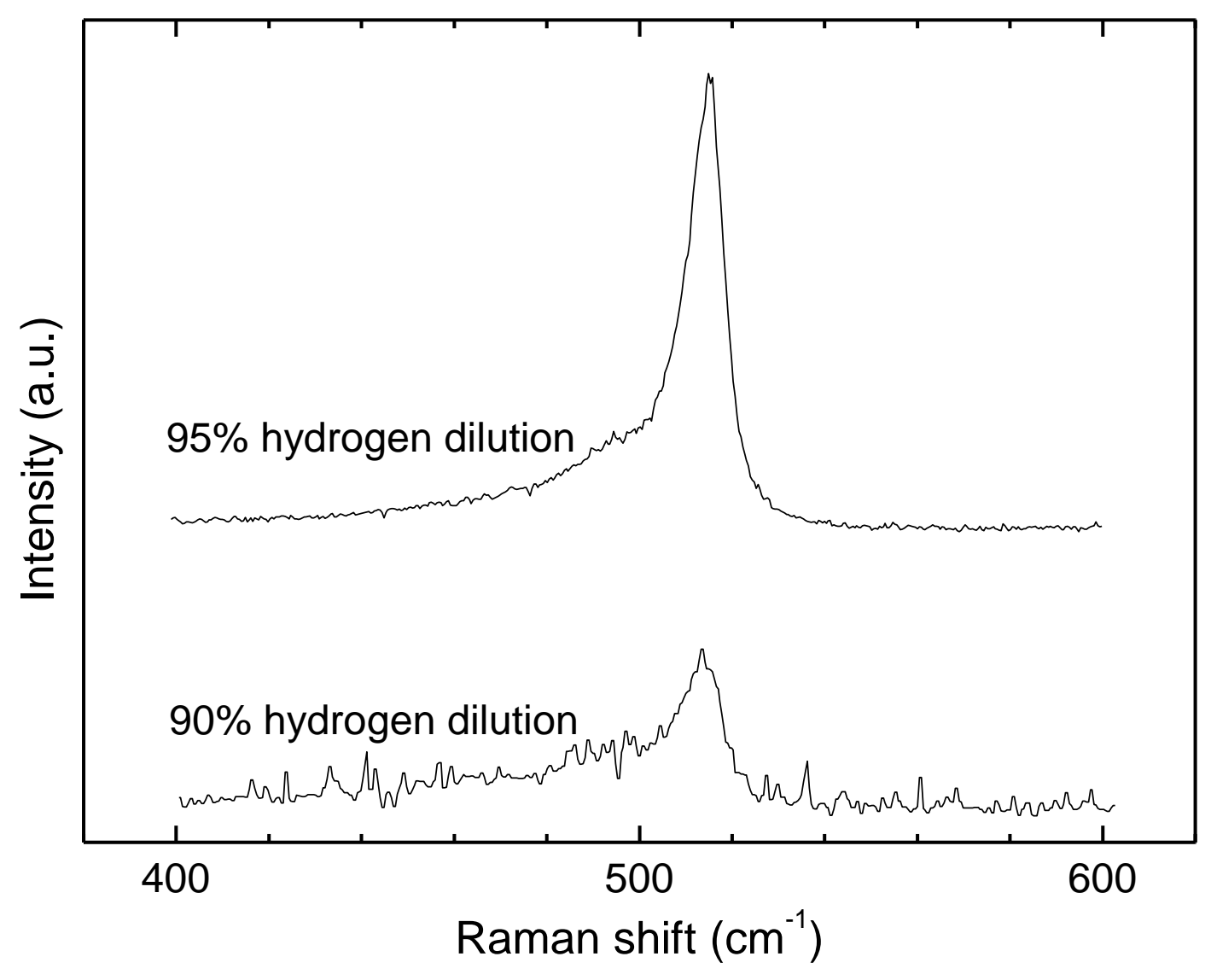

Fig. 2. C.Voz et al. 


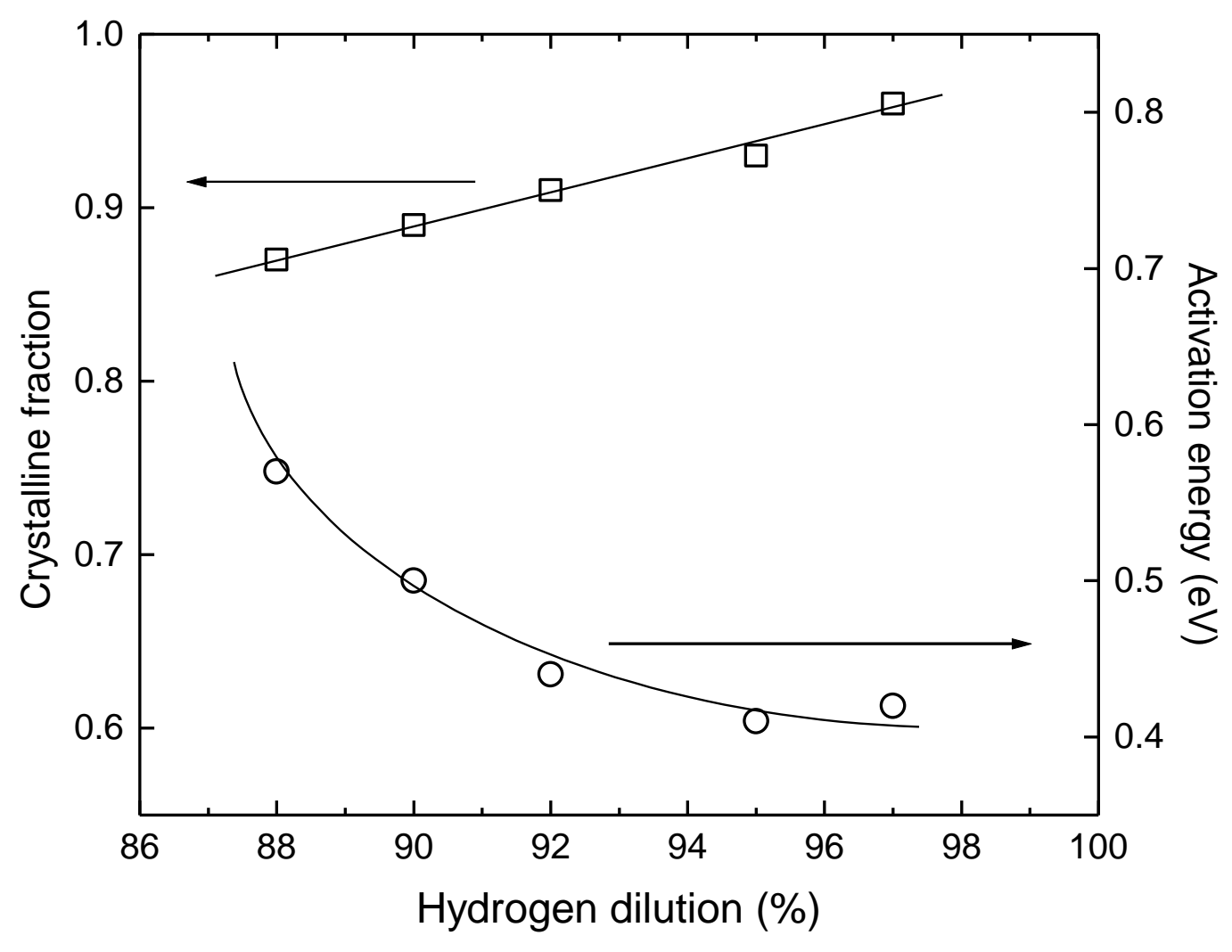

Fig. 3. C.Voz et al. 


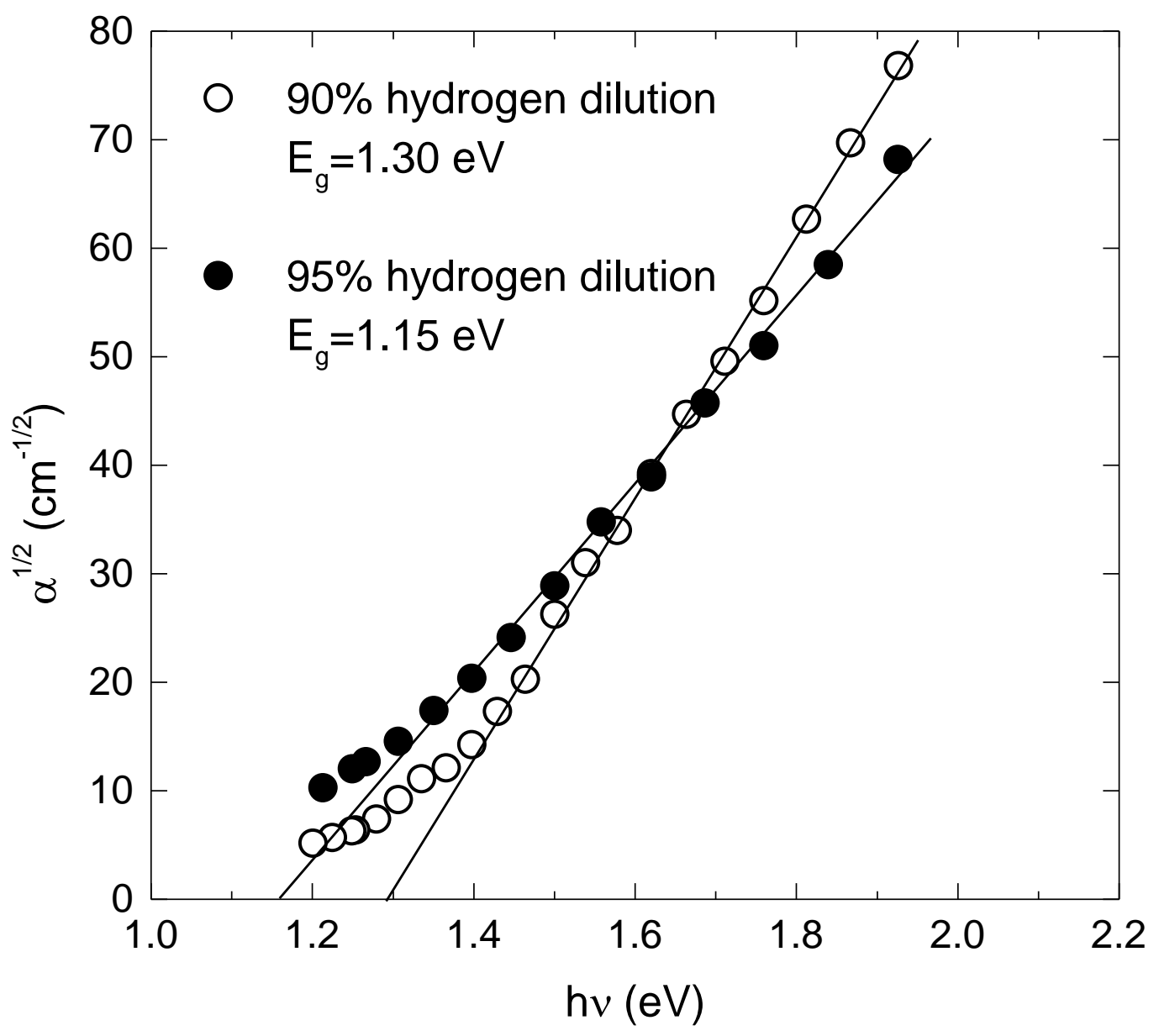

Fig. 4. C.Voz et al. 


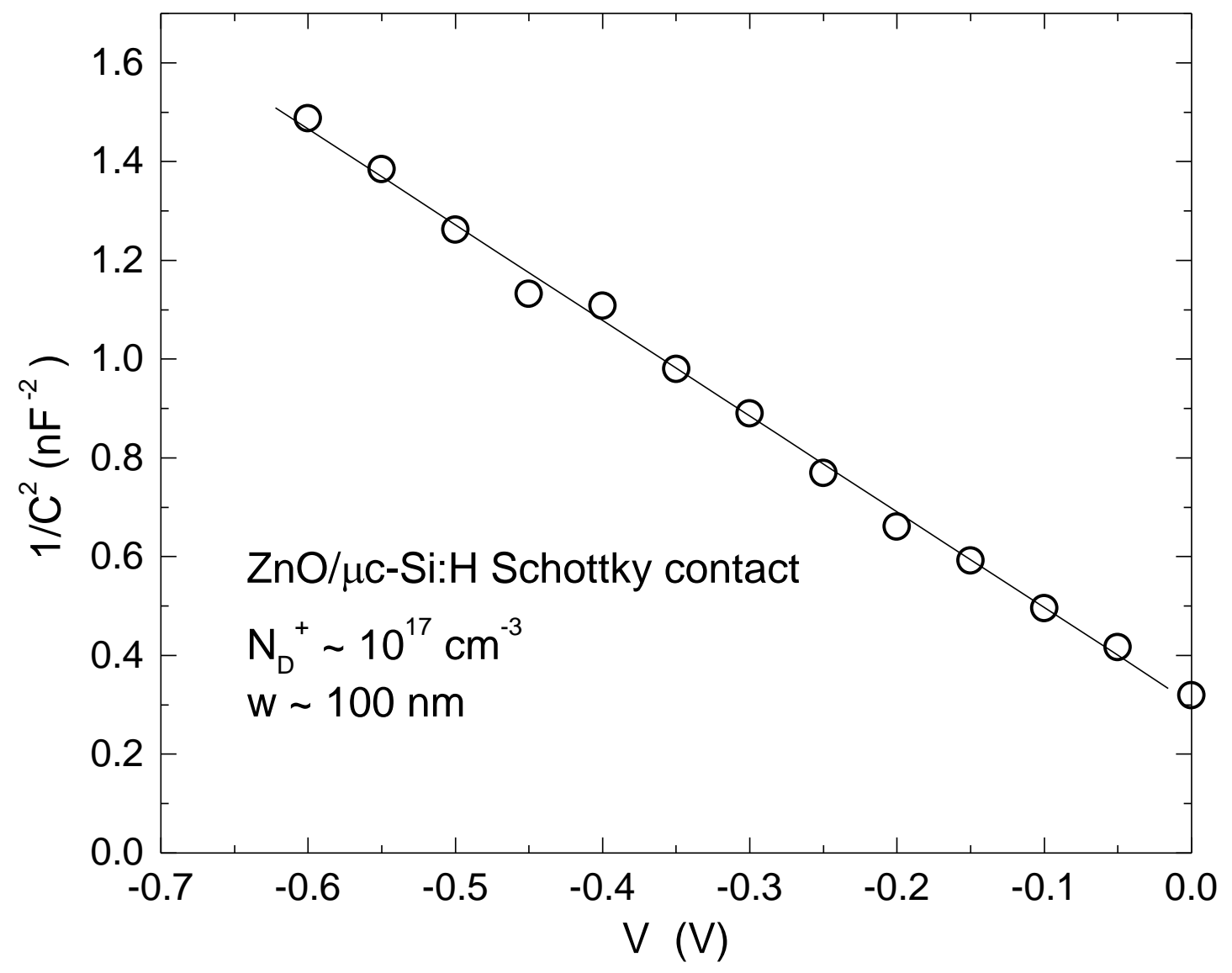

Fig. 5. C.Voz et al. 


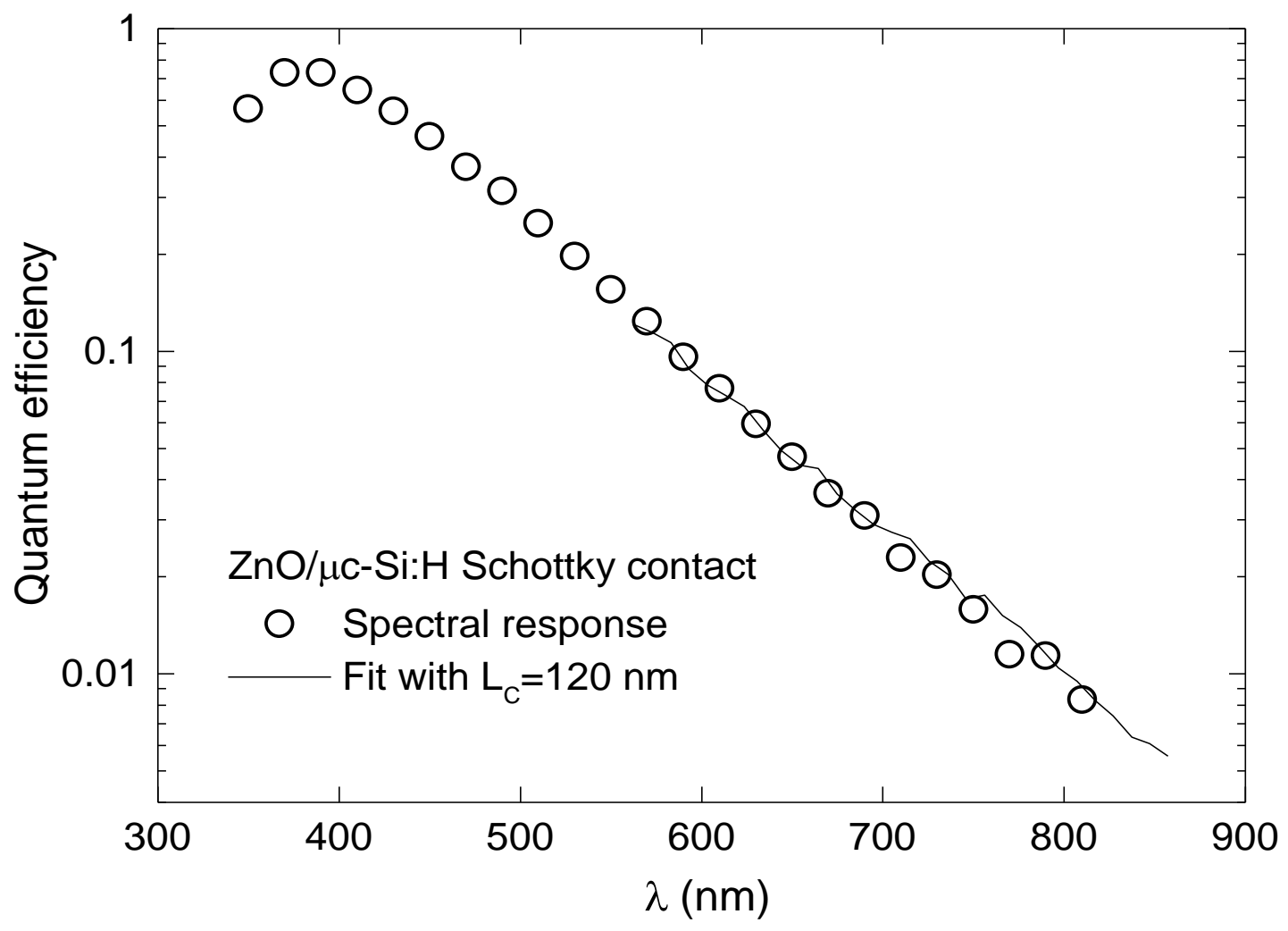

Fig. 6. C.Voz et al. 


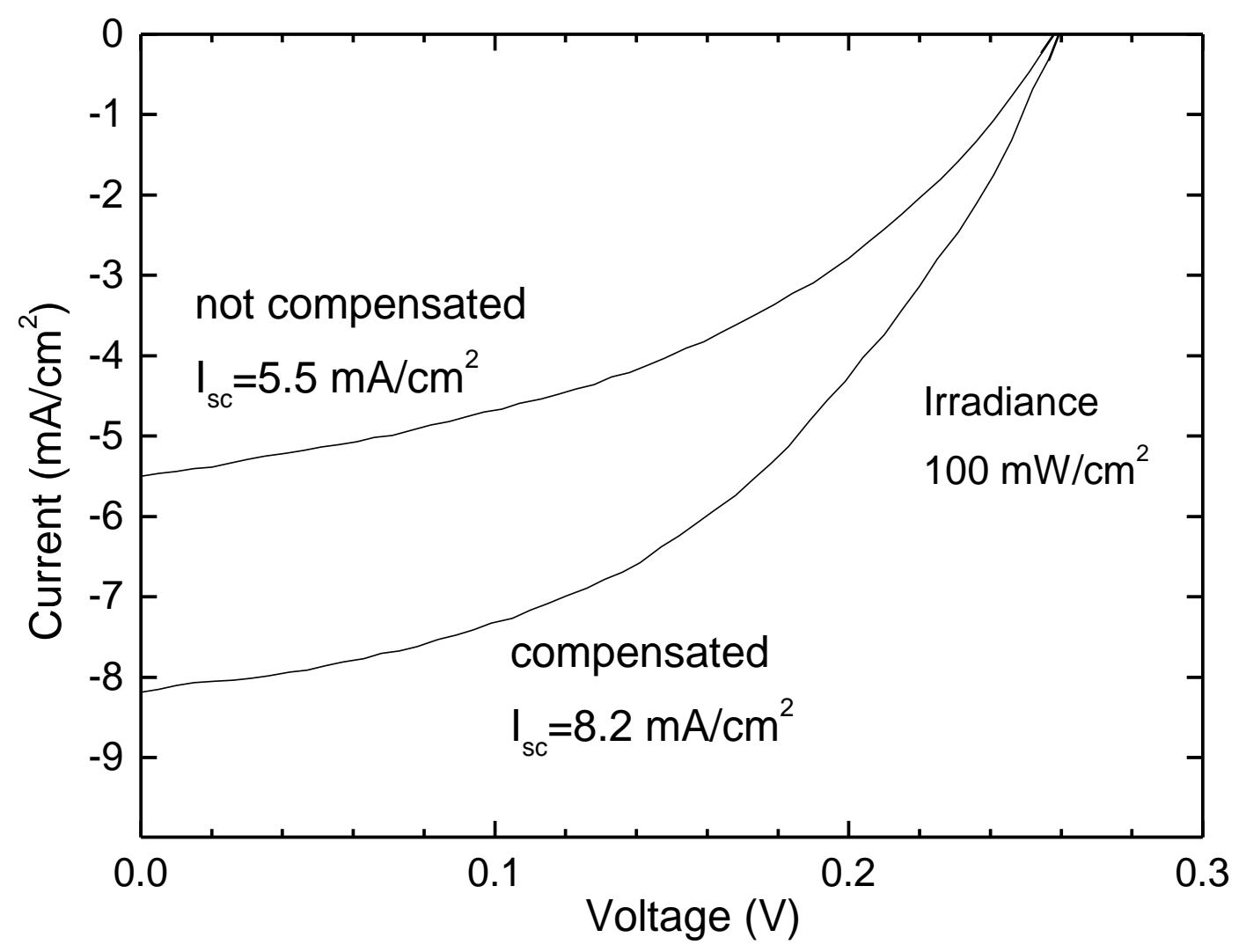

Fig. 8. C.Voz et al. 


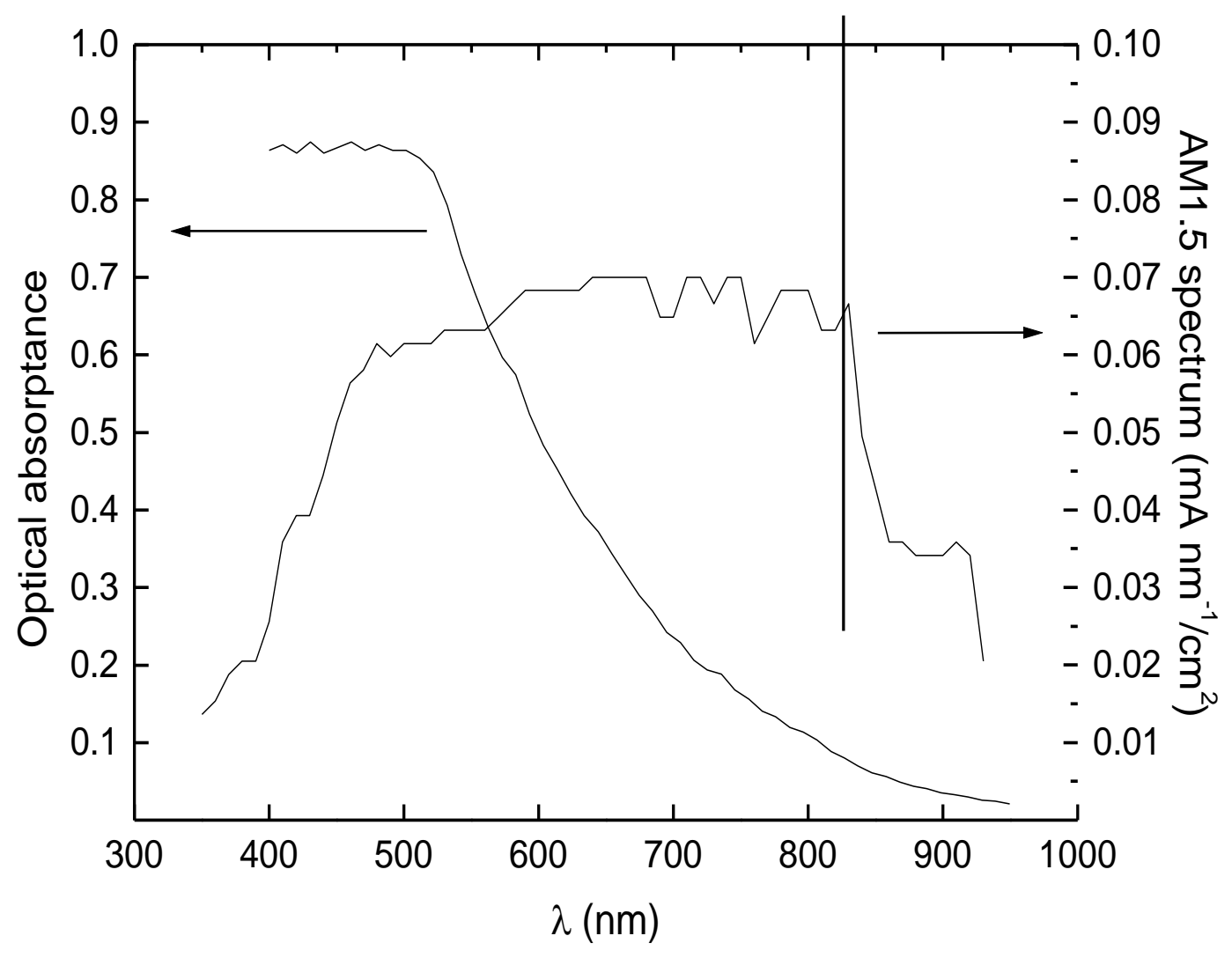

Fig. 7. C.Voz et al. 


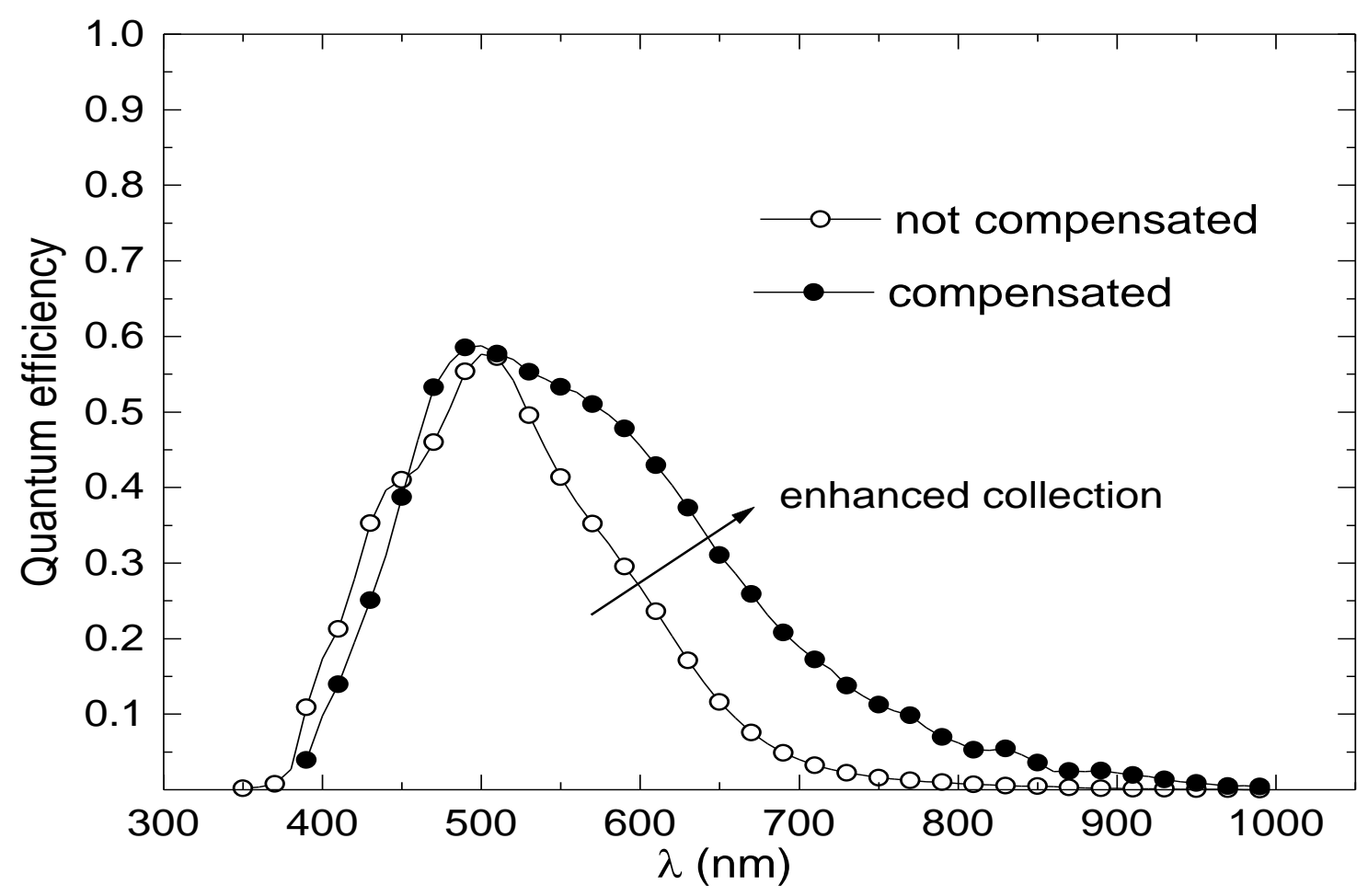

Fig. 9. C.Voz et al. 